\title{
Eva Gårding
}

\section{0-2006}

Eva Gårding died on January 1, 2006, at the age of 85. She was born and grew up in Landskrona in the south of Sweden. She started her academic career relatively late. In the beginning of her professional life, she was a much appreciated high-school teacher of modern languages. She earned her doctoral degree in phonetics at Lund University in 1967 with the

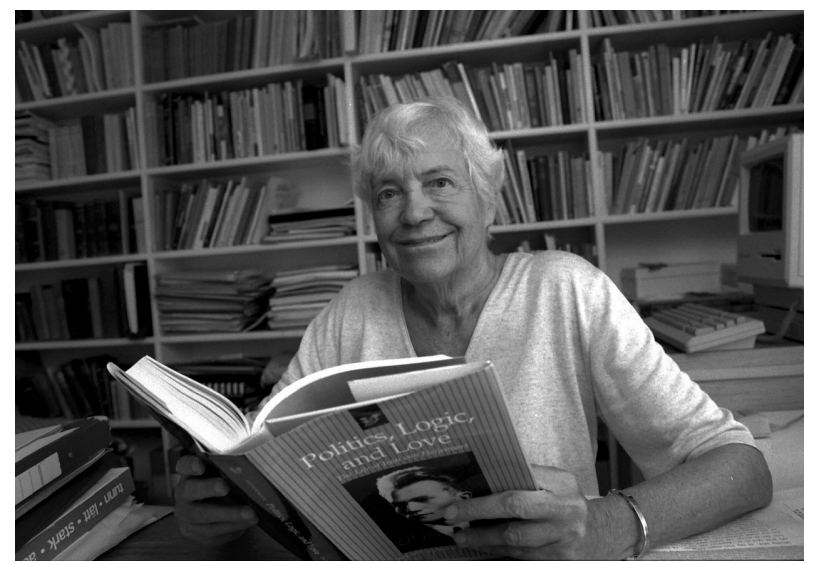
thesis Internal Juncture in Swedish. During the 70s she held a position as a lecturer in phonetics in the Department of Linguistics and Phonetics at Lund, and between 1980 and 1986 she had the chair of phonetics in the same department. During her career as a phonetician, she was a visiting guest researcher at, among other places, Haskins Laboratories and the Research Institute of Logopedics and Phoniatrics, Tokyo University. She was the initiator of the Nordic Prosody Conferences, the first meeting of which was held in Lund in 1978. Together with Prof. Hiroya Fujisaki she was the organizer of an international symposium on intonation in connection with the International Congress of Linguists in Tokyo in 1982. She was also specially invited to several international conferences as a moderator or plenary lecturer, among them the International Congress of Phonetic Sciences in Copenhagen in 1979, the AILA World Congress in Lund in 1981, and the International Congress of Phonetic Sciences in Utrecht in 1983. Eva Gårding also served as Head of the Department of Linguistics and Phonetics in Lund for a number of years, and for a period she was a member of the working committee for linguistic research on the Swedish Research Council.

Eva Gårding's research in phonetics was devoted, in particular, to the study of speech prosody. Although her scientific career did not start until the age of 40 , her achievements within the field of prosody and intonation are impressive. Her scholarly work consisted of both basic research and to some extent also applied research. Her studies of prosody included work on a number of different languages. Even if her

\begin{tabular}{ll}
\hline KARGER & @ 2007 S. Karger AG, Basel \\
Fax +4161306 12 34 & $\$ 23.50 / 0$ \\
E-Mail karger@ karger.ch & Accessible online at: \\
www.karger.com & www.karger.com/journals/pho
\end{tabular}


research was mainly on Swedish, the prosody of English, French, Greek, Hungarian, Chinese and Kammu was also the object of her great interest. A typical feature of her research work was specifically the contrastive comparison of the prosody of two or more languages. Her understanding of prosody was often formulated in terms of a 'generative' model, which also allowed testing by means of synthetic speech. Her name is associated particularly with the so-called Lund intonation model, which presents a pattern for other intonational modelling and has been widely spread internationally.

Her research on the Swedish language was primarily devoted to dialectal variation, to which prosody makes an important and fundamental contribution. But she also focused on other aspects such as prosodic expressions of the statement/question dichotomy, phrasing and textual organization. Eva Gårding approached the study of prosody from several distinct angles. First and foremost, she used regular acoustic analysis of prosody. She also exploited physiological techniques, and for instance carried out EMG studies of larynx muscles in speech. Furthermore, she conducted a number of perceptual experiments, typically based on synthetic speech. With her background as a teacher of modern languages, Eva Gårding took a strong interest in language pedagogy and pronunciation teaching. In her applied research, she was engaged in developing such a methodology. It was particularly aimed at Swedish as a second language, which was a focus of interest in the 70s, as a consequence of the fairly extensive immigration into Sweden from a variety of different cultures, which took place at the time.

For Eva Gårding cooperation in scientific work was important. Through the years she had a fruitful interaction with a number of different scientists, both at home and abroad. From the late 70s, she was the leader of two pioneering research projects in Lund, one devoted to basic research, 'Swedish Prosody' (supported by the Swedish Research Council), the other one, 'Optimization of Swedish Pronunciation' (supported by the Bank of Sweden), with a more applied goal. Another important project led by her was the LUCLA project (Swedish Research Council), a collaboration between phonetics at Lund and at UCLA, aimed at phonetic descriptions of some non-European languages: Arabic, Chinese and Hausa. She was also the leader of a project on language and brain (Swedish Research Council). It is to be noted that at the time (70s and 80s) big research projects in the Humanities were relatively rare in Sweden. During this time she was also the supervisor of several PhDs. As a retired professor of phonetics, Eva Gårding was still very active in prosodic research. She continued to take part in scientific exchange for many years, and until quite recently she played an important role in the discussion at the phonetics seminar in Lund. Together with her husband Lars, a mathematician, she instituted a prize (the Gårding Prize) to be awarded scholars of great merit who are active in Sweden, alternating yearly between mathematics and linguistics/phonetics.

Eva Gårding had great personal splendour. She had a special ability to inspire students and get them irresistibly involved in scientific thinking. She was a very good teacher as well as a very good writer. For her, a scientific report was not only a work of science, but equally importantly, a work of art. This is apparent from her own scientific writings, where precision, clarity and elegance are characteristic features. She was also a very sharp critic. Her perspicacity allowed her to immediately discover flaws in reasoning and weak points in an argument, and she was wise enough not to be overly consenting and complying. Eva Gårding was also a very good friend. Her house was always open to phonetics students, colleagues, guest researchers and scientists visiting from all parts of the world.

Gösta Bruce, Lund 